\title{
SISTEMA DE INTELIGÊNCIA INTEGRADA EM COMUNICAÇÃO AUTOMOTIVA URBANA
}

\author{
Fabio Pires ${ }^{1}$, Eduardo Mario Dias ${ }^{2}$, Felippe da Silva Pires ${ }^{3}$, Caio Fernando Fontana ${ }^{4}$ \\ ${ }^{1}$ Escola Superior de Administração e Gestão - ESAGS/STRONG/FGV \\ ${ }^{2,4}$ Escola Politécnica - Universidade de São Paulo - USP \\ ${ }^{3}$ Universidade Santa Cecília - UNISANTA \\ E-mails: fabio.pires@esags.edu.br,emdias@pea.usp.br, \\ felippepires90@hotmail.com, caioffontana@uol.com.br
}

\section{RESUMO}

Muitas tecnologias existentes são interativas e capazes de se comunicarem instantaneamente em áreas pré-estabelecidas urbanas, como centros comerciais, empresariais, industriais, assim como rodovias inteligentes. Com a utilização sistêmica das tecnologias TIC e ITS é possível elaborar um sistema virtual, com inteligência integrada, com comunicação automotiva interativa online, em áreas urbanas, no uso direto e indireto dos sinais dos smartphones, tabletes, celulares, GPS, entre outros. E nesse artigo, o objetivo principal é apresentar a comunicação dos vários sinais inerentes dos equipamentos para desenvolver uma inteligência correlativa para melhorar o fluxo de veículos em horários de grandes picos, seja utilizando o Sistema Inteligente de Transporte (SIT, sendo ITS em inglês), que integra as várias tecnologias, com aplicações avançadas, melhorando e tornando mais eficiente e seguros os sistemas de transportes, utilizando as entradas e saídas para o processamento de informação e comunicação, controle e ações de comandos e respostas do gerenciamento e operação dos sistemas de transportes. Também é apresentado o problema encontrado nos horários de picos, pelos congestionamentos de tráfego nas áreas urbanas e nas estradas principais que ligam as grandes cidades. Consequentemente perde a mobilidade e tem falta de segurança, assim como também prejudica o Meio Ambiente, piorando a qualidade do ar. Como consequência há prejuízos econômicos, sociais e psicológicos para todos os usuários, sejam públicos ou privados em função da morosidade e atraso dos compromissos firmados. E para resolver ou mitigar o problema se faz necessário a utilização de tecnologias existentes, como a TIC e o ITS integrados, com estratégias de gestão que permitam viabilizar melhores resultados aos usuários, empresas e governos.

\section{INTRODUÇÃO}

Existem muitas tecnologias que podem ser agregadas e compartilhadas umas com as outras, sem a necessidade de investimentos vultosos, como as que se utilizam dos sinais de comunicação existentes. Nesse trabalho todas as centrais de controles se comunicam entre si utilizando comunicação de dados, VolP (voz sobre IP) e 
imagens de vídeos pela rede virtual da central SVOI, permitindo uma visão global e local do trânsito, em uma gestão operacional integrada.

A importância dos meios de transportes no desenvolvimento econômico e social das comunidades urbanas e rurais, e devido a necessidade de mobilidade para o transporte de pessoas, cargas e animais acabam aumentando, de forma significativa, o número de veículos em circulação e consequentemente, propiciam frequentes congestionamentos do trânsito, seja urbanos ou nas estradas intermunicipais.

A perturbação psicológica causada pelo "stress" do trânsito tem preocupado as autoridades, porque esses distúrbios acabam resultando em trágicos acidentes, brigas e discursões constante entre motoristas, em função da lentidão do trânsito.

O sistema de posicionamento global, conhecido por GPS (Global Positioning System) é um sistema de navegação, composto por satélites, que permite ao equipamento receptor móvel saber sua localização, como outras grandezas, em qualquer instante, desde que o receptor esteja no campo de visão dos satélites GPS.

Apresenta a central de monitoramento, com as antenas receptoras, câmeras de vídeos inteligentes, que permite que haja uma integração entre todos os sinais de rádios recebidos por veículos e pessoas, provenientes de celulares, rádios de comunicações, smartphones, GPS, entre outros, onde as antenas receptoras estão instaladas nas principais ruas, avenidas, entradas e saídas da cidade, e estão instaladas em localizações estratégicas, conjuntamente com a central de monitoramento no centro da cidade.

Com o crescimento populacional no Brasil e mundo, existe a necessidade de fazer adequações nas infraestruturas existentes e mais ainda, adequar a necessidade da mobilidade humana, com as tecnologias de interconectividade utilizadas pelos usuários, como celulares, rádios de comunicação, smartphones, etc. via satélite, antenas, sistemas wireless, permitindo a integração de todos os sistemas inteligentes existentes. E, portanto existe a distribuição lógica de comunicação, entre os equipamentos de campo, dispositivos e centro de controle, em que os sinais de rádio advindos dos celulares, smartphones, tabletes, entre outros são enviados as antenas receptoras instaladas em vários pontos da cidade ou estradas rodoviárias e são enviadas ao centro de monitoramento para controle de trânsito.

Os sinais de rádios emitidos pelos celulares ou equivalentes, transportados por pessoas, seja caminhando ou no veículo, são captados pelas antenas receptoras, codificados e transmitidos à central de monitoramento e controle. Como resultado é possível verificar o trânsito pelas câmeras fixas e móveis instaladas na cidade e rodovias para tomada de decisão quanto ao tempo de semáforos e mobilidade.

No geral são apresentados o sistema ITS, o problema encontrado, com uma das soluções, a central virtual, o GPS, os resultados, a conclusão e as referências bibliográficas. 


\section{SISTEMA INTELIGENTE DE TRANSPORTE - ITS}

O sistema Inteligente de Transporte (SIT), em inglês Intelligente Transportation Systems (ITS), visa integrar várias tecnologias, com programas e aplicações avançadas, com objetivo de melhorar e tornar mais eficiente e seguros os sistemas de transportes.

Os ITS buscam a integração dessas inteligências tecnológicas utilizando as entradas e saídas para o processamento de informação e comunicação, pelo sensoriamento, controle e ações de comandos e respostas do gerenciamento e operação dos sistemas de transportes (SILVA, 2000). Podem ser categorizados por:

a) Sistemas Avançados de Transportes Públicos (APTS);

b) Sistemas Avançados de Gerenciamento de Tráfego (ATMS);

c) Sistemas Avançados de Informação ao Viajante (ATIS);

d) Operação de Veículos Comerciais (CVO);

e) Sistemas Avançados de Controle Veicular (AVCS);

f) Coleta Eletrônica de Pedágio (ETC).

Os países europeus, asiáticos e americanos têm obtidos resultados surpreendentes com a implantação desses sistemas, porque aumentam a fluidez do trânsito, diminuem os acidentes e contribuem para o Meio Ambiente.

\section{PROBLEMA ENCONTRADO E SOLUÇÃO NECESSÁRIA}

O principal problema encontrado nos horários de picos são os congestionamentos de tráfego nas áreas urbanas e nas estradas principais que ligam as grandes cidades ou regiões metropolitanas. Consequentemente existe a perda de mobilidade e falta de segurança, assim como também o aumento da incidência de gases na atmosfera, piorando a qualidade do ar. Como consequência há prejuízos econômicos, sociais e psicológicos para os usuários, em função da morosidade e atraso dos compromissos assumidos.

Pergunta-se:

Como resolver ou diminuir este problema grave de congestionamento das grandes cidades e vias de acessos nos horários de picos?

Como evitar o caos do trânsito nas grandes metrópoles e o stress causado nos usuários?

Para resolver ou mitigar o problema se faz necessário a utilização de tecnologias existentes, como a TIC e o ITS, com estratégias de gestão operacional e técnica que permitam viabilizar melhores resultados aos usuários, empresas e governos.

Além da construção de mais infraestrutura, se faz necessário maiores investimentos em Sistemas Inteligentes de Transporte, visto que propiciam melhores condições de mobilidade entre os veículos e principalmente redução de acidentes e emissão de gases poluentes. 


\section{SISTEMA VIRTUAL DE OPERAÇÕES INTEGRADAS (SVOI)}

Esse conjunto de sistemas pode ser agregado em um único sistema de comunicação e operação, numa Central Virtual de Operações Integradas, onde pode ser compartilhada com outros sistemas de comunicações (figura 01).

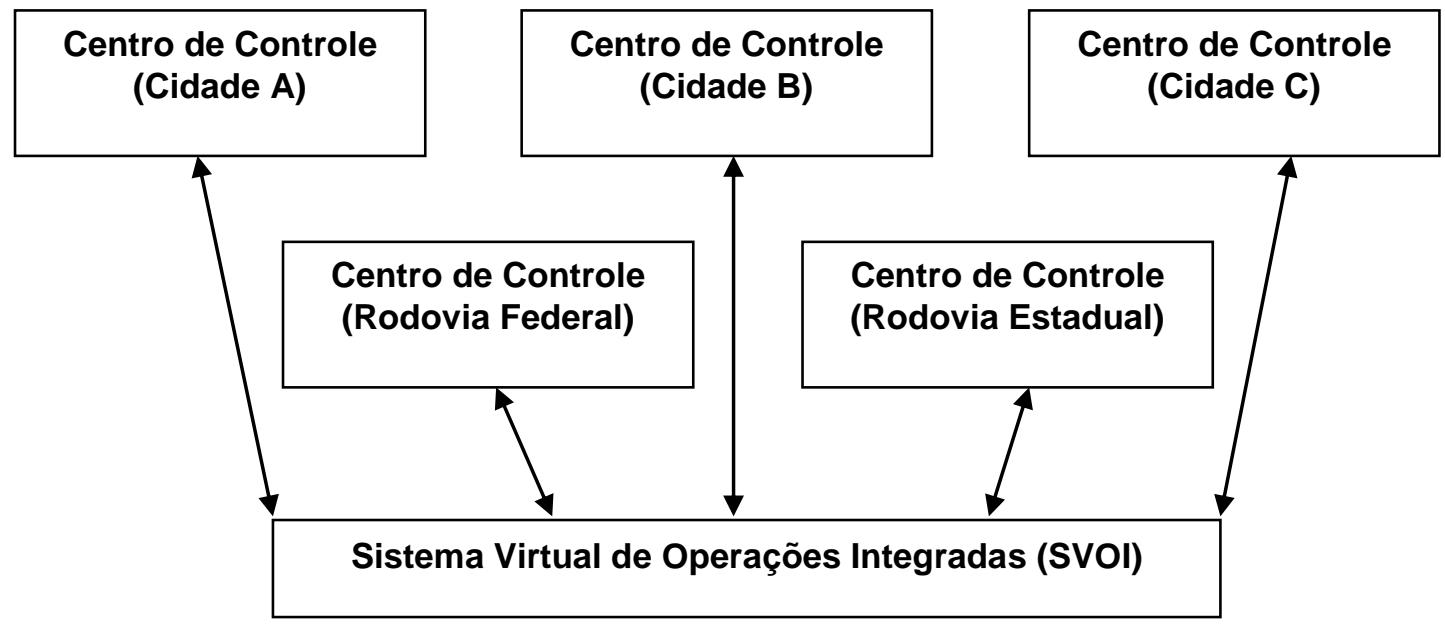

Figura 01. Sistema Virtual de Operações Integradas (SVOI).

Todas as centrais de controles se comunicam entre si utilizando a comunicação de dados, VoIP (voz sobre IP), imagens de vídeos pela rede virtual do SVOI. Como resultado, pelo uso do sistema SVOI, pode-se ter uma visão global e local do trânsito, em uma gestão operacional integrada.

Os meios de transportes influenciam diretamente no desenvolvimento econômico e social das comunidades urbanas e rurais, principalmente porque precisam de mobilidade para 0 transporte de pessoas, cargas e animais. E devido a essas necessidades acabam aumentando, de forma significativa, o número de veículos em circulação e consequentemente, frequentes congestionamentos do tráfego, seja nos trânsitos urbanos ou nas estradas (FIGUEIREDO, 2005).

O efeito psicológico causado pelo "stress" do trânsito tem preocupado as autoridades governamentais, pois acaba resultando em trágicos acidentes, entre outras, como briga constante entre motoristas, resultante da morosidade e lentidão do trânsito.

$\mathrm{Na}$ figura 02, tem-se um demonstrativo dos resultados esperados com a implantação de ITS nos centros urbanos.

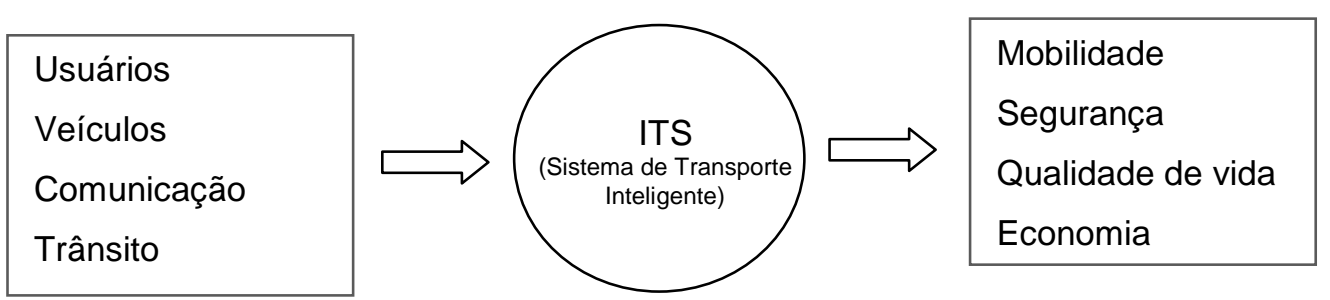

Figura 02. Resultados esperados com a implantação de ITS. 
O Sistema de Transporte Inteligente reúne várias tecnologias de informação, comunicações e controle, utilizando as infraestruturas dos sistemas de transportes públicos e privados e dos próprios veículos e usuários, possibilitando o monitoramento do fluxo do trânsito, a fim de reduzir os congestionamentos e propiciar alternativas aos motoristas, aumentar a produtividade, salvar vidas, poupar tempo e dinheiro, reduzindo os impactos na saúde e no ambiente (FIGUEIREDO, 2005).

Para a comunidade europeia, três pontos são cruciais para o transporte europeu e mobilidade urbana:

1. Segurança;

2. Poluição e Saúde;

3. Congestionamento urbano e interurbano.

As tecnologias automotivas estão avançando de forma tão pró ativa, que em breve, com o uso maciço de veículo autônomos, o número de acidentes serão bem menores, como também a mobilidade urbana melhor. Várias experiências nesse sentido estão sendo desenvolvidas na Europa, América e Ásia (DUARTE, LIBARDI, SANCHEZ, 2007).

\section{GPS - GLOBAL POSITIONING SYSTEM}

O sistema de posicionamento global, conhecido por GPS (Global Positioning System) é um sistema de navegação, composto por um conjunto de satélites, que permite ao equipamento receptor móvel saber sua localização, como também o tempo e clima, em qualquer momento localizado na Terra, desde que o receptor esteja no campo de visão dos satélites GPS.

Para auxiliar na mobilidade urbana e deslocamento móvel se utiliza o GPS Veicular, figura 03.

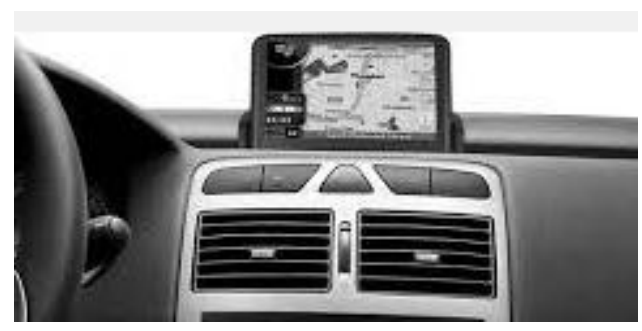

Figura 03. GPS veicular

Este tipo de equipamento é muito utilizado pelos carros de passeios, como nos veículos de cargas, visto que oferece uma gama de informações uteis aos usuários. Como por exemplo: A rota entre duas ou mais cidades, estados ou dois pontos de referências entre bairros, ruas e avenidas. 


\section{SISTEMA INTEGRADO DE MONITORAMENTO VIRTUAL}

O sistema é composto de uma central de monitoramento, antenas receptoras, câmeras de vídeos inteligentes, que permite que haja uma integração inteligente entre todos os sinais de rádios recebidos por veículos, pessoas, provenientes de celulares, rádios de comunicações, smartphones, GPS, entre outros (PIRES, 2009).

$\mathrm{Na}$ figura 04 é possível observar as posições de várias antenas receptoras, englobando as principais entradas e saídas da cidade, divididas por quadrantes, assim como a localização estratégica da central de monitoramento no centro da cidade.

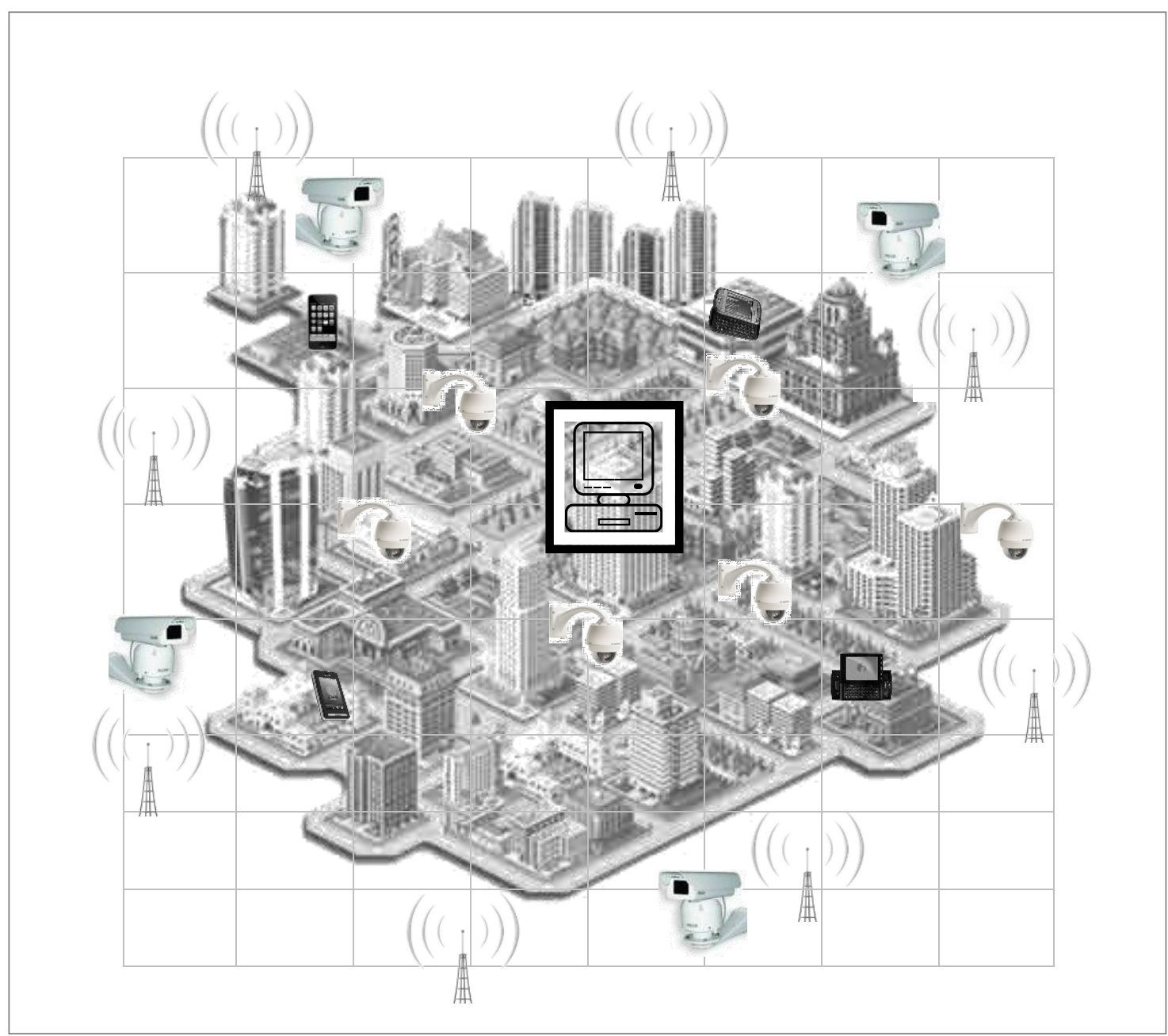

Figura 04. Desenho ilustrativo da cidade, com antenas, câmeras e central de monitoramento.

O sistema de monitoramento (SVOI) é dividido por 64 quadrantes (8x8), de Norte a Sul e Leste a Oeste, cobrindo toda área geográfica da cidade.

Descrição.

... Antenas receptoras de ondas de Radio. 
...Central de Monitoramento (SVOI).

... Câmera de Vídeo Móvel PTZ - Pan, Tilt, Zoom.

Câmera de Vídeo Móvel Dome.

\subsection{Sistema tecnológico de controle veicular integrado ao sistema ITS}

A população brasileira e mundial cresce anualmente e, consequentemente, existe a necessidade de fazer adequações nas infraestruturas existentes e mais ainda, adequar a necessidade da mobilidade humana, com as tecnologias de interconectividade utilizadas pelos usuários, como celulares, rádios de comunicação, smartphones, etc. via satélite, antenas, sistemas wireless, permitindo a integração de todos os sistemas inteligentes existentes, como apresentado na figura 05 (PIRES, et al. 2012).

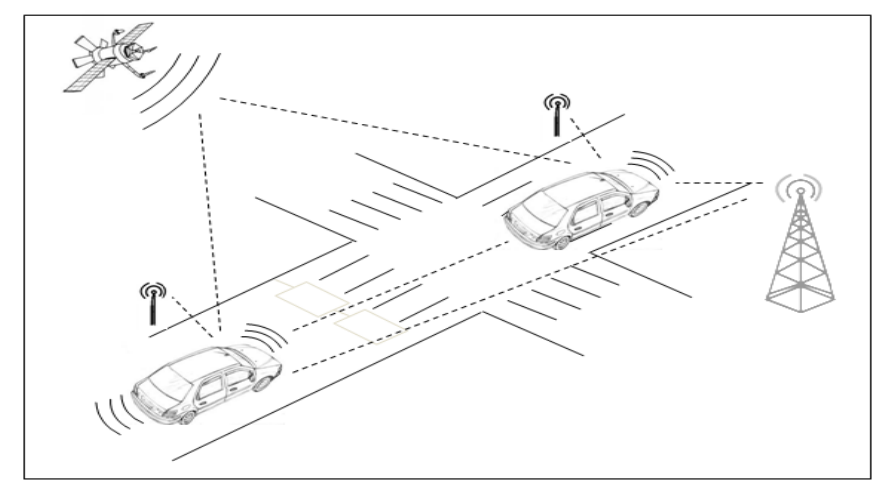

Figura 05. Esquemático dos sistemas integrados de segurança e ITS

Com o sistema ITS, as tecnologias implantadas nos veículos, e o centro de monitoramento SVOI, permite um novo ciclo da informação tecnológica integrada, que reduz significadamente os acidentes automobilísticos (SAKURAI, 2014).

\subsection{Distribuição física do sistema}

Existe a distribuição lógica de comunicação, conforme figura 06, entre os equipamentos de campo, dispositivos e centro de controle, em que os sinais de rádio advindos dos celulares, smartphones, tabletes, entre outros são enviados as antenas receptoras instaladas em vários pontos da cidade ou estradas rodoviárias e são enviadas ao centro de monitoramento para controle de trânsito (MASHRUR, 2003).

Os sinais de rádios emitidos pelos celulares ou equivalentes, transportados por pessoas, seja caminhando ou no veículo, são captados pelas antenas receptoras, 
codificados e transmitidos à central de monitoramento e controle. Como resultado é possível verificar o trânsito pelas câmeras fixas e móveis instaladas na cidade e rodovias para tomada de decisão quanto ao tempo de semáforos. Visto que todo equipamento de comunicação emite sinal de radio, onde é possível fazer um rastreamento desse sinal ao longo de sua trajetória.

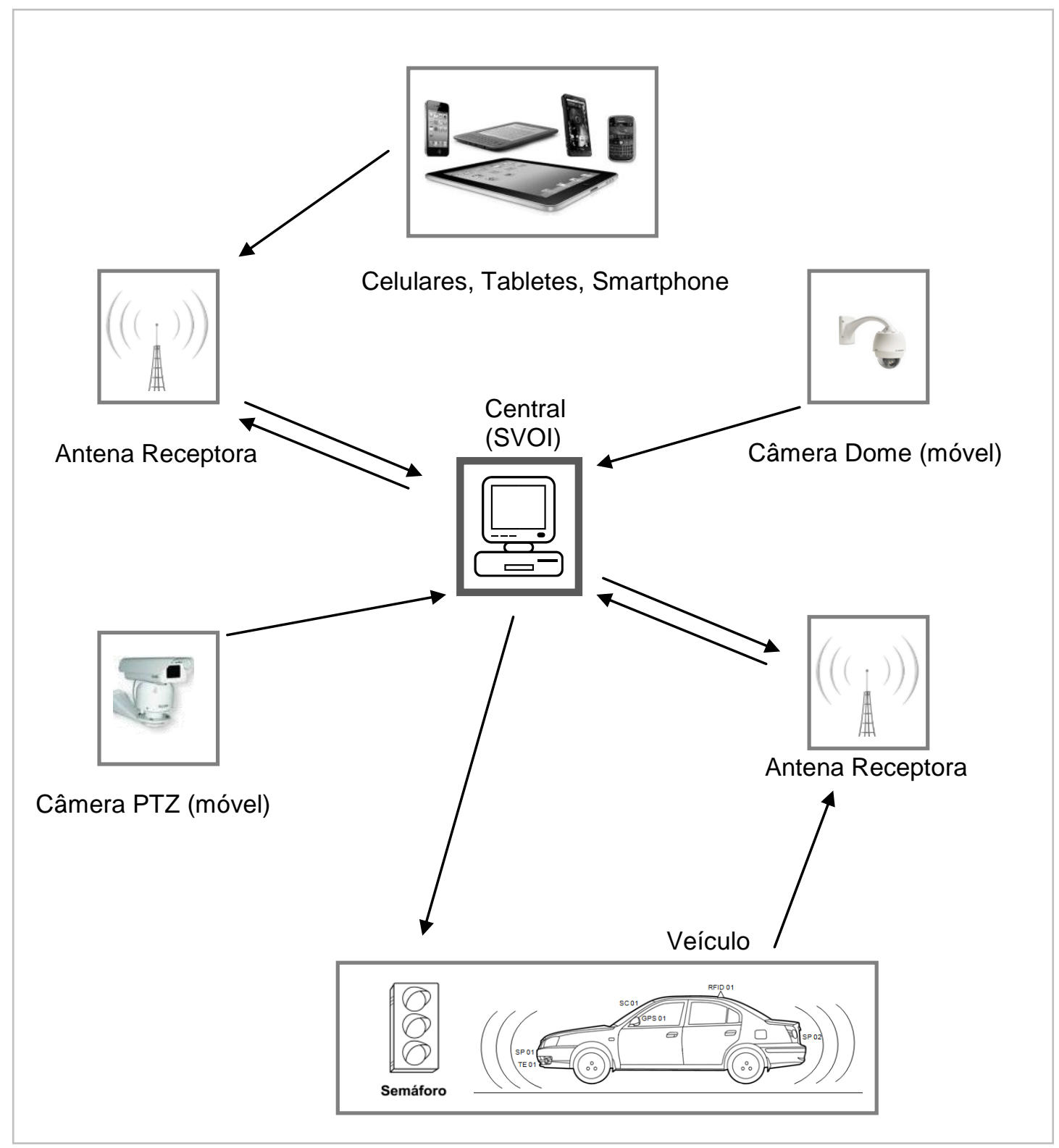

Figura 06. Desenho ilustrativo do sistema de comunicação entre equipamentos, dispositivos de campo e Centro de Controle.

\section{PROPOSTAS TECNOLÓGICAS PARA MELHORAR A MOBILIDADE URBANA}

Para melhorar a mobilidade e acessibilidade de pessoas, bicicletas, cadeirantes, veículos de passeios, cargas e de transportes coletivos, como também dos demais meios de locomoção e modais, dentro do planejamento urbano, com a integração 
das tecnologias TIC e ITS, Tecnologia da Informação e Comunicação e Sistema Inteligente de Transporte urbano integrado entre cidades de regiões metropolitanas (FRANCO, 2008).

a) Implantar o Plano de Mobilidade Urbana;

b) Desenvolver programas de Mobilidade Urbana com Tecnologia, Inovação e Sustentabilidade;

c) Melhorar o acesso para o deslocamento de pessoas e móveis, em tempo ideal, com segurança, tecnologia e conforto;

d) Comunicação, sinalização e fluidez de trânsito na concentração e aglomeração de pessoas e veículos em grandes eventos;

e) Preparar a cidade para o adensamento populacional e crescimento econômico e social.

\subsection{Acessibilidade urbana}

a - Calçadas para todos os usuários, com padronização e acessibilidade;

b - Modernização da rodoviária, com estacionamentos integrados;

c - Integração do VLT às linhas de ônibus por rotas, com bilhete único e programas de estímulo ao uso de bicicleta;

\subsection{Trânsito e Transportes}

a) Faixas de segurança para motociclistas e Implantação de novas ciclovias e de bicicletários;

b) Semáforos inteligentes nos principais corredores de trânsito;

c) Acessibilidade nas ruas e praças para pessoas com deficiência ou limitação física;

d) Interatividade das condições do trânsito na Internet, celulares, tabletes e smartphones;

e) Sistema eletrônico de venda de cartão de estacionamento.

f) Central de monitoramento inteligente integrando os meios de transportes e trânsito.

\subsection{TIC, ITS e SVOI}

a) Implantação da central de monitoramento virtual SVOI;

b) Instalação de antenas receptoras;

c) Softwares de integração lógica.

\section{CONCLUSÃO}

Com a utilização dos sinais transmitidos por equipamentos de usuários, tais como celulares ou rádios de comunicação, seja se locomovendo a pé, de bicicleta ou veículo motorizado, é possível desenvolver um sistema de inteligência integrada de comunicação urbana, onde virtualmente, com os sinais disponibilizados pelos usuários possa ter uma central dinâmica integrada com outras centrais, mostrando a situação em tempo real e on-line da mobilidade urbana local ou geral de uma cidade ou região, pelo uso de algoritmos e modelos matemáticos de gestão. 


\section{REFERÊNCIAS}

[01] SILVA, Danyela Moraes. Sistemas Inteligentes no Transporte Público Coletivo de Ônibus. Porto Alegre. UFRGS. 2000. 144 p. Dissertação (Mestrado em Engenharia) - Programa de Pós-Graduação em Engenharia, Universidade Federal do Rio Grande do Sul, 2000.

[02] Figueiredo, Lino Manuel Baptista. Sistemas Inteligentes de Transporte. Porto. 2005. 277 p. Tese (Doutorado em Engenharia) - Programa de Pós-Graduação em Engenharia, Universidade do Porto, 2005.

[03] DUARTE, Fabio; LIBARDI Rafaela; SANCHEZ, Karina. Introdução à Mobilidade Urbana. Curitiba. Juruá. 2007.

[04] PIRES, F. Metodologias de automação integradas ao centro de controle, comunicação, operações e segurança - CCCOS para o sistema de segurança portuário. São Paulo. USP. 2011. Dissertação (Mestrado em Engenharia Elétrica) Programa de Pós-Graduação em Engenharia, Universidade de São Paulo. 2011.

[05] PIRES, F.; FONTANA, C. F.; DIAS, E. M.; PIRES, F. S. Sistema de segurança integrado para o controle interno e externo dos veículos automotores. São Paulo. SIMEA 2012.

[06] SAKURAI, C. A. ; Marte, LC ; YOSHIOKA, L. R. ; FONTANA, C. F. Integrating Intelligent Transportation Systems Devices using Power Line Communication. INTERNATIONAL JOURNAL OF ENERGY, v. 8, p. 36-42, 2014.

[07] MASHRUR A. Chowdhury, Adel Wadid Sadek. Fundamentals of Intelligent Transportation Systems Planning. Norwood. Artech House. 2003.

[08] FRANCO, Celso. Transito como eu o entendo: a ciência da mobilidade humana. Rio de Janeiro. E-papers. 2008. 